\title{
The integration of science and medicine into sports training
}

Every athlete's body consists of a unique assemblage of physical attributes. In order to maximise performance, these attributes must be trained and honed, but this can be a difficult task as the inner workings of an athlete's body are not visible to the naked eye. Sometimes, an athlete's particular skill-set reveals information about the inner workings of their body. For example, an athlete who can sprint quickly is likely to have fast-twitch fibres as part of their bodily assemblage. But in many cases, it is very difficult for an athlete or coach to determine the exact state of the actor-network inside the body.

This problem is generally solved by enrolling sports scientists and medical professionals into the sporting arena. Indeed, experts in sports science and medicine are now assumed to make up a significant part of a competitive athlete's actor-network. These experts have a range of technological tools at their disposal that are able to reveal the inner workings of the body and suggest solutions. For example, doctors may take blood tests in order to test whether an athlete's body is lacking in any particular type of nutrition. If this is the case a specialist dietician or nutritionist may be enrolled in order to solve the problem.

This chapter investigates the processes used by athletes and coaches to integrate sport scientists into the sporting context. While it would be easy to assume that enrolment would easily take place because athletes, coaches and scientists all have the common goal of improving performance, the two cases in this study demonstrate that the integration process is more complex and encompasses a range of perspectives and understandings, as well as specific actants, that contribute to enrolment or non-enrolment.

\section{The development of sports science and medicine}

Sports medicine has not always existed as a discipline. Instead, it has grown in line with the development of modern sport. Waddington (1996, p. 177) defines sports medicine as 
the more or less systematic application of the principles of medicine and science to the study of sporting performance, and the institutionalization of this practice in the form of professional associations, research establishments, scientific conferences and journals.

Waddington (1996) describes how sports medicine came into being as a discipline in the 1920s and 1930s: the first college of sports medicine was created in Germany in 1924, and the first use of the term 'sports medicine' is recorded as occurring in 1928. However, it was after the 1950s that the growth of the discipline really accelerated. Waddington (1996) argues that this came about as a result of the medicalisation of society, which encompassed sport, and the increasingly competitive nature of sport. These two influences resulted in sports science and medicine becoming normal and recognisable parts of modern sporting practice. Several authors (Safai, 2007; Theberge, 2008; Waddington, 1996) have established that the integration of sports scientists into sports training programmes has come to be seen as an important path to improving performance. Moreover, Safai (2003) acknowledges that the constant stream of injured athletes provides regular work for sports scientists, leading to them being easily integrated into the field. Therefore, it is not surprising that sports medicine has flourished and, more recently, come to incorporate some complementary or alternative practitioners alongside the traditional physicians and physiotherapists (Theberge, 2008).

Consequently, the modern athlete is understood as surrounded by a range of support staff with scientific or medical expertise who assist with ensuring the he or she performs at maximum capacity. For example, Theberge (2008, p. 21) describes the range of sports medics that made up the medical delegation for the Canadian Olympic teams in 2004 and 2006:

At the 2004 Athens Olympics, the Canadian medical delegation included medical doctors, physiotherapists, athletic therapists, chiropractors, massage therapists and psychologists. At the 2006 Olympics in Turin, the delegation included these professions, and the addition of a nutritionist.

Similarly, large medical teams are frequently used to support professional sport. For example, Lance Armstrong had a three-member medical team assisting him, which was not questioned as unusual until Armstrong's doping scandal, when all three members were banned together with Armstrong (Vinton, 2012).

Within the sociology of sport, attention has been paid to the role of scientists in its risk culture (Nixon II, 1992; Safai, 2003), the history and development of sports medicine as a discipline (Safai, 2007; Waddington 1996, 2000); 
and the specific roles of and power relations between different sports medicine professions (Malcolm D., 2006; Theberge, 2008). However, there has been only little attention paid to the enrolment processes through which sports scientists become part of the sporting network. Exceptions include Nixon's (1992) study, where the concept of the 'sportsnet' is utilised to describe how athletes and coaches identify external resources, Pike's (2005) exploration of how rowers step outside the traditional medical framework in order to identify alternative practitioners and my own (2012) examination of how gymnasts in New Zealand enrol sports scientists. The case studies in this chapter are drawn from the work of Pike (2005) and myself (2012), with a view to understanding how it is that athletes make choices about utilising various practitioners. The cases are similar in the sense that neither the rowers nor the gymnasts have formal access to sports medicine support as part of their training regime, meaning that both the gymnasts and rowers (and/or at times their coaches) must make their own arrangements in order to access medical support.

\section{The study of medicine through ANT: the work of Annemarie Mol}

A theorist who has received significant acclaim for her ANT-orientated work is Annemarie Mol. In The Body Multiple: Ontology in Medical Practice, Mol sets out to investigate 'the way the tensions between sources of knowledge and styles of knowing are handled inside present-day allopathic medicine' (Mol, 2002, p. 1). Mol's work is of relevance, since this chapter examines the integration of sports medicine and sports medical professionals into sport, where similarly there are tensions regarding knowledge sources and ways of knowing.

Mol (2002) emphasises that she is interested in multiple understandings and not perspectives. She argues that the term 'perspective' refers primarily to a point of view, or a particular meaning, whereas, in line with ANT, her view is broader than that, in aiming to incorporate physical reality. She is not only interested in the meanings ascribed to particular instances of the body; she is also interested in the body itself, and in the non-humans artefacts attached to medicine that allow different understandings to co-exist. She argues that the term 'perspective' refers only to a way of thinking, whereas 'understanding' incorporates a physical reality.

Mol is also interested in how diseases come into being. She observes that diseases do not exist until they have been identified by the medical team, and 
then they come into being with a range of associated treatments. She argues that diseases are thus 'performed' (Mol, 2002, p. 32) by doctors and patients, together with a range of heterogeneous actants such as a microscope, which allows the doctor to identify particular signs and 'produce' the disease. Her argument aligns with the argument made in the previous chapter that substances only come into being as banned once WADA identifies them as banned and includes them on the banned list. Both arguments emphasise the way that identification by a medical team of diseases or substances transforms them from a range of apparently innocent symptoms or chemicals into potential 'evils'.

Thus far in this book there has been little attention to the methods used by ANT theorists, primarily for the reason that there are very few studies of sport that utilise an ANT methodology to draw on. Mol's ethnography, however, provides an excellent example of the ANT methodology at work.

In one sense Mol undertook a traditional ethnography. She located a setting, in her case a Dutch hospital, where she situated herself and undertook extensive observation. Mol (2002, p. 3) describes her experiences:

I observed technicians handing diagnostic tools in the vascular laboratory. I followed the tracks of radiologists and pathologists in their leadings with leg arteries. I went for months to the weekly meetings where the treatment options for patients with complicated cases of vascular disease were discussed. I witnessed several operations. Spent some days in the research laboratory of the haematologists. Held interviews or had conversations with epidemiologists, physiologists, internists, surgeons, and general practitioners. A couple of them read my articles and we talked about their reactions. I also went to the library and studied the textbooks and journal articles written, or mobilised as a resource, by 'my doctors' and, when the references and my curiosity took me there, compared them with other publications. For two years I followed the monthly research colloquium on atherosclerosis. I co-authored with a junior doctor an article about the introduction of a diagnostic protocol. I supervised a medical student who interviewed vascular surgeons in several smaller hospitals and another one who analysed discussions about the intake of cholesterol. And finally, I had the temporary luxury of a research assistant ... who held long patient interviews, transcribed them, talked them over with me, and co-authored publications about this material.

The actions Mol describes here are very similar to a traditional ethnographic account in the sense that she describes immersing herself in the hospital environment and observing and talking to a wide range of participants. However, the first line indicates that there is a substantial difference between Mol's work and that of the 'normal' ethnographer. Mol begins by stating that she 'observed 
technicians handing diagnostic tools. By describing the observation of tools as her opening, Mol indicates her intention not merely to observe people, but also to observe objects, in line with ANT methods. She argues that through considering objects, or non-humans, and the way they act, it is possible for multiple, rather than singular, realities to be revealed. The method that Mol employs in her work enacts the argument that humans and non-humans should be considered as of equal importance in the production of reality. She pays equal attention to humans and non-humans.

The structure of Mol's book draws attention to a further aspect of the ANT method. Each page of the book has two sections. It has a 'main' narrative, which is in a standard-sized font and takes up half to three-quarters of the page. But below that, in a subtext, is a different narrative. The upper narrative consists entirely of the description of Mol's time in the hospital. Encounters are described, field notes are recorded and interviews are quoted. Below that, in a separate section, is the reference to literature that is expected as part of standard academic method. Mol separates these sections because ANT argues that the descriptive narrative provides sufficient information without the need for a formal explanation. Latour $(2005$, p. 147) expands on the need for a detailed description to stand on its own as the method for understanding a situation:

What is meant by a 'social explanation' most of the time? Adding another actor to provide those already described with the energy to act. But if you have to add one, then the network was not complete ... I have never seen a good description in need of an explanation.

By a 'good description' Latour refers to a description of sufficient detail that takes into account both human and non-human actants. He argues that providing a description of this nature allows the explanation to be revealed without the need for further work. Mol's account of the hospital is what Latour would term a 'good description, as in the upper (main) section of the book Mol does indeed provide a highly detailed account of the hospital while paying attention to both humans and non-humans.

What follows are two case studies. While the first uses work from a traditional ethnography, the second is one of the few sports studies that adopts an ANT approach. As such, the second case consists predominantly of description. 


\section{Case study: the enrolment of sports medical practitioners by female rowers in the UK}

Elizabeth Pike's study of rowers in the UK provides a useful account of the different understandings held by medical professionals and athletes, and the consequences in terms of enrolment of sports scientists. Pike performed a two-year ethnography of two women's rowing clubs in the south of England with a goal of examining their medical support in a bid to begin to remedy the lack of research into the practices of sports medicine. Because the findings reveal the use of alternative rather than traditional medical practitioners, Pike notes the different understandings that those with different roles bring to the athletic body and the resultant tensions between these understandings. Her argument resonates strongly with Mol's observations of the way different medical professionals hold different sets of understandings which affect how they operate. The following considers two of the understandings identified by Pike: the bio-medical paradigm and the sport ethic.

\section{The bio-medical paradigm}

Pike (2005) observes the dominance of the bio-medical paradigm within both researchers of sports medicine and medical practitioners. She describes how researchers agree that the bio-medical model has dominated Western medicine throughout the twentieth century (see, for example, Nettleton and Gustafsson, 2002; Wade and Halligan, 2004). The bio-medical model can be summarised as resting on the following five key assumptions (Nettleton and Gustaffson, 2002):

1. The mind and the body are treated as separate entities, with mental phenomena considered in isolation from physical symptoms.

2. The body is treated as though it is a machine and therefore doctors are understood as akin to engineers.

3. It is assumed that the most effective way of healing what is viewed as an unwell body is through technological intervention.

4. Diseases and illnesses are explained in terms of biology without consideration of social and psychological factors.

5. Every symptom, disease or sign is understood as being caused by a specific, identifiable agent. 
In Mol's (2002) terms, these five assumptions combine to form a particular understanding of the body. This is the understanding that many in the medical profession bring when encountering an athletic body. Related to the bio-medical model is the sport ethic, which similarly works as a particular understanding of how elite athletes should behave.

\section{The sport ethic}

Hughes and Coakley (1991) argue that sport is dominated by a particular understanding of the body that they refer to as the 'sport ethic'. They describe how 'the sport ethic refers to what many participants in sport have come to use as the criteria for defining what it means to be a real athlete' (Hughes and Coakley, 1991, p. 308). The four dimensions that are agreed to make up the sport ethic are: extreme dedication to sport, a drive to distinguish oneself through sport, accepting risk and playing through pain, and rejecting any obstacles that stand in the way of success (Hughes and Coakley, 1991; Malcolm N., 2006; Sefiha, 2012).

Several researchers have identified how athletes learn to take on these understandings through the messages they receive from sports coaches, sports officials, other athletes and the media (Hughes and Coakley, 1991; Malcolm N., 2006). Specifically, Malcolm N. (2006) identified how athletes are socialised into adhering to the sport ethic through coaches making light of athletes' injuries, ignoring complaints about pain and demonstrating adherence to the sport ethic. The behaviour resulting from adhering to the sport ethic may be deemed deviant, as it may consist of disordered eating, overtraining or playing through injury, but the underlying motivations are viewed as positive owing to their role in achieving highly in sport (Sefiha, 2012). Therefore the components of the sport ethic act as behaviour expectations for athletes involved in competitive sport.

Pike (2005) found that the rowers in her study both adopted and rejected the above two understandings, which led to them dealing with injury differently and enrolling different forms of treatment. First, she found that many of the rowers and coaches accepted injury as a natural part of rowing. This belief was rationalised through an understanding that rowing technique involves 'twisting the back to one side, knee compression, and repetitive wrist movements', which inevitably lead to injury (Pike, 2005, pp. 203-204). Yet it also conforms to the sport ethic through demonstrating the way that athletes accepted the risk of injury and the assumption that it would be necessary to play through pain as 
entirely normal. Further evidence of conforming to the sport ethic was found through the way the majority of rowers said that they would continue to train with their injury, despite being aware that further damage might be caused.

The desire of athletes to conform to the sport ethic at times ran counter to the advice they received from doctors. Doctors were described as not understanding sport, which led the rowers to lack faith in their diagnosis or advice. This was particularly the case if the doctor's advice ran counter to their own beliefs regarding how they should behave as an athlete. For example, many of the rowers expressed dissatisfaction that their doctors told them to rest. Rest was not seen as an option for the rowers, since they felt the need to continue training to ensure their 'place in the boat' (Pike, 2005, p. 204). This reflects the strength of the sport ethic in the way that athletes expressed a wish to do everything they could to remain part of the rowing team, and therefore did not see rest as an option. Furthermore, the reaction of the rowers in feeling that this advice was insufficient also suggests that the rowers had taken on the belief in the bio-medical model in expecting doctors to be able to fix their problem. The assumption is that a doctor will be able to identify the problem and fix it, in line with the notion that there are particular symptoms that can be fixed through identifying a specific agent and intervening technologically to fix it. Instead, the doctor simply prescribed rest and/or painkillers without fixing the problem.

In perceiving painkillers to be insufficient, the rowers demonstrated their expectation that any technologies or techniques utilised by doctors should be able to do more than simply mask the pain. This suggests that the rowers were uninterested in enrolling technologies or techniques that did not fix the problem, owing to their belief in the bio-medical model. Consequently, their understanding made them reluctant to enrol the pain killers and, by extension, the doctors who prescribed them.

The dissatisfaction with the doctors led some of the rowers to choose 'alternative' practitioners instead. Pike (2005) suggests that the rowers preferred these practitioners because of their holistic, whole-body understanding, which differed from the bio-medical paradigm. The rowers described how doctors would not treat them as 'people', instead adopting the view of them as a machine to be fixed. By contrast, the rowers enjoyed the collaborative aspect of the alternative treatments, where they were able to be an active participant in their treatment rather than being treated as a passive machine. Pike notes how the active nature of their participation was indicative through the language used, with doctors seeing 'patients' and alternative practitioners seeing 'clients'. 
Pike (2005) notes that cost was another factor in determining the choice to visit an alternative practitioner. She observes that traditional medicine is covered by government funding, while visiting an alternative practitioner is not, as determined by government policy. As with doping, this demonstrates the power of inscriptions in determining outcomes. The policy inscription in this case did not allow the government to cover visits to alternative practitioners, thereby making it difficult for those without disposable income to do so. The actor-network for alternative medicine includes the policy inscription as an anti-programme that could only be overcome through the presence of sufficient funds to cover the cost of visiting.

Pike (2005) also found cases where athletes chose to accept one practitioner's advice over another. For example, she describes how a rower she called Sally saw a consultant surgeon about her shoulder injury who advised her that she required surgery, but by contrast, she saw an osteopath who told her it was fine. Sally followed the advice of the osteopath since it allowed her to keep training. In Mol's (2002, p. 32) terms, this example demonstrates the concept of diseases, or injuries, being 'performed'. Sally's consultation with the surgeon produced an injury in need of fixing, in line with the bio-medical model's understanding that medical problems require technological intervention in order to be fixed. In contrast, the injury disappeared through her consultation with the osteopath. Mol (2002) also discusses how different practitioners' views on a problem clashed at times, and when they did, the findings from one were given more weight than the other.

Pike's (2005) study suggests that the different understandings held by rowers and practitioners resulted in different levels of enrolment, though enrolment was not the focus of Pike's study. Rather, her study focused on the different understandings, which were similarly important in Mol's work. Acknowledging that enrolment may not occur as a result of the existence of different understandings is a significant part of the theory of enrolment. As discussed earlier, enrolment is unable to occur without the alignment of different points of view or, as Callon (1986) described it, intéressement. As Callon and later Latour (1991) note, intéressement does not mean that all parties must agree and have the same motivations, only that all parties must have an agreement that enrolment is beneficial. In Pike's (2005) case, the athletes frequently chose not to enrol mainstream medical practitioners because they believed it would not be beneficial because of the very different understandings held by 
themselves and the medical parties, encapsulated in the contrast between the bio-medical model and the sport ethic.

Identifying the link between the viewpoints of the different parties and the enrolment process is one of ANT's most significant contributions. Many theoretical approaches focus on the identification of the viewpoints held by particular groups, such as the work of theorists who identified the sport ethic and the bio-medical model. ANT is not interested in what makes up these points of view per se, but provides a process for identifying the impact these different understandings have on action taking place. In this example, the important point is that the contrasting points of view led to non-enrolment, or a lack of action, between the athletes and traditional medical practitioners, rather than the exact points of view themselves being the focus.

The next example continues the exploration of the enrolment (or non-enrolment) of sports scientists through examining the sport of gymnastics in New Zealand. However, unlike Pike's (2005) study, this study stems from my own research, in which I deliberately used the ANT method of 'following the action' (Latour, 1987).

\section{Case study: the enrolment of sports scientists into the sport of gymnastics in New Zealand}

In previous chapters of this book I introduced the ANT concept of enrolment in order to examine the integration of technologies into the sports environment. In the following case the concept of enrolment is again employed in order to understand how different understandings of sport and medicine, such as those discussed in the case of the rowers, influence whether sports scientists are enrolled by athletes or coaches. The case study used here is one of the few ANT studies that have been conducted in sport, and examines how gymnasts and coaches in New Zealand enrol or choose not to enrol sports scientists to work with them as part of their training regime.

\section{Methods}

In line with the ANT perspective, this study used ethnographic methods where 'actants' (Latour, 1991; 1999a; 2005) such as gymnasts, coaches, sports scientists and sport policy documents were followed through the process of creating gymnastics. 'Following' refers not to the round-the-clock observation of individuals, 
but to a 'mapping of the moments' (Michael, 2000, p. 131) when gymnastics makes its appearance. This research mapped the moments in which elite gymnastics and its integration with sports science occurred.

The mapping began with the aim of observing all the elite training gymnasiums in New Zealand. I visited and observed all ten elite gymnastics training venues in the country and spent a minimum of two full days observing at each. Depending on my access, the period of observation was usually much longer and in some cases weeks or months of weekly observations took place, along with interviews with any consenting participants at the gymnasium. The process of interviewing involved seeking out participants who appeared to be informed and competent. Finding informed participants is a key aspect of all sociological research that Latour argues is equally significant and necessary in ANT (Farnsworth and Austin, 2005; Latour, 2005; Simpson, 2007). Formal interviews took place with forty-seven participants, ranging from gymnasts, coaches and judges to parents, administrators and scientists, all of whom are referred to by pseudonym and role within this chapter. All were heavily involved in the sport at the elite level and therefore highly informed about the workings of the sport. Some other participants declined to be interviewed formally but agreed to answer informal questions by email or in person.

In the interviews I asked the gymnasts and coaches to describe which sports science services they had utilised and to explain how this had occurred. Similarly, I asked the sports scientists to describe how they had worked with gymnasts and how such arrangements had come about. A definition of 'sports scientist' was not given to the participants; instead they were invited to interpret the term in whichever way they wished. The most commonly discussed sports scientists were physiotherapists, nutritionists, psychologists and biomechanists, and participants revealed a range of methods for enrolling them into the gymnastics network, as described below.

\section{One-off enrolment}

While some highly successful athletes enrolled scientists through a government-funded system known to athletes as 'carding', very few athletes were able to access funding to enrol scientists in this way. Instead, the most common enrolment of scientists occurred as one-off enrolments. These would occur with the coach, gymnast or gymnast's parents enrolling a scientist to assist with a specific issue. Usually these enrolments were for a single session only, with the scientist being paid for their work by the gymnast or their parents. 
The majority of gymnasts had at some point attended a joint session with either a nutritionist or a psychologist in order to provide them and their parents with general information and skills. Some gymnasts, such as the trampolinist Esmerelda, described how they had attended a large number of these sessions at sports camps for talented athletes of all ages. In other cases, such as one the women's gymnastics coach Jessica described, it was something that the coaches organised in the gymnasium, asking each gymnast to pay a small amount to cover the scientist's fees. Mary, a rhythmic gymnastics coach, described how she found group sessions like these extremely useful both as a way of imparting new knowledge and as a reminder, using the example of how she enrolled a dietician for a one-off session:

Dietician is the other one I use occasionally, and invite the parents. They prepare the meals and do the shopping. And that's where you get some interested and some not, but most of the parents are pretty good. Even the ones who are trained in nutrition say it's still good to hear it.

Mary emphasised the importance of the parents as part of the gymnastics actor-network, as those who prepare the meals for the gymnasts. She acknowledged that parents are empowered to control the diet of the gymnasts and was happy that most chose to utilise the knowledge gained from these sessions to benefit the gymnasts. Enrolment was easy to achieve because the parents, coach and dietician all perceived the dietician to be directly helpful in ensuring the gymnasts remain healthy while training through receiving the correct nutrition. Their exact reasons for believing this varied, with some there to improve athlete health and others for performance enhancement, but regardless of individual motivation, enrolment occurred and action took place in the form of an education session by a dietician.

In contrast to Mary's example, other coaches and athletes said they found nutrition sessions disappointing as the information was not necessarily specific to their sport or their situation. Gilbert (2009) confirms how many sports are under-represented in the sports nutrition literature, making it challenging for the sports nutritionist to work with athletes from these sports. Mike described the difficulty in finding a nutrition expert who understood the long and demanding training hours of gymnastics:

I don't believe that a lot of the nutritionists actually know gymnastics well enough to give expert advice. Which is not to say they couldn't learn, they've obviously got the knowledge but they don't know the sport well enough to help. 
Esmerelda, a trampolinist, agreed with Mike, describing how many sports science sessions she had attended focused on other sports, including artistic gymnastics, but omitted trampolining:

How do I apply it to tramp(oline)? They've based it on netball and rugby and they'll go 'how many rugby players? How many cricket players?' (Artistic) gymnastics is totally represented, but I went with another rhythmic gymnast once and they didn't mention our sports (trampolining or rhythmic gymnastics) once the whole time ... That's the hard thing, finding someone - and I mean, where would you find someone that's trampoline specific?

In these cases, although scientists are enrolled in the sense that they provide an educative talk and receive payment, full enrolment is not achieved because the gymnasts and coaches are not enrolling the knowledge imparted by the scientist. Often, one reason for knowledge not being enrolled is a lack of understanding on both sides about the athletes' requirements. For example, in his discussion of eating practices of rhythmic gymnasts, Johns (1998) describes a case of a nutritionist struggling to assist a gymnast because the gymnast was unable to explain the exact weight she was required to be. Johns highlights how, although the judges and coaches have an idea about how a gymnast should ideally look, this is not always translated into a form that a nutritionist is able to help with. In the New Zealand study, Kelly, a rhythmic gymnastics coach, described how she solved this problem by translating the needs of a rhythmic gymnast into the need to be at the lowest end of the healthy weight range. When one of Kelly's gymnasts and her mother visited a nutritionist, Kelly instructed the mother to ask the nutritionist for advice about how to stay at this weight, an instruction the nutritionist was able and willing to work with. Therefore in this case, the translation provided by Kelly allowed enrolment to occur.

The role that Kelly played in providing this translation contrasts strongly with other studies of gymnasts' eating behaviour that identify gymnastics coaches as requiring athletes to eat very little and retain a very thin body shape regardless of the health consequences (see, for example, Johns and Johns, 2000; Kerr and Stirling, 2012; Ryan, 1995). Few solutions to this culture have been identified. Further research examining the role that translators of any form may play in ensuring gymnasts and other at-risk athletes remain healthy within environments with stringent expectations may be of benefit.

Participants identified nutritionists as one of the most commonly enrolled scientists by both parents and coaches. Whitson et al.s (2006) study of the 
knowledge level of sports coaches in the USA about assisting athletes with eating disorders found that the coaches acknowledged the necessity of having knowledge of nutrition and eating disorders, and that they would have liked more education about these matters. However, Whitson et al. do not question how enrolment may occur in situations where the nutritionist and coach are not able to agree on a goal or articulate their needs, which is where employing an ANT perspective could be of value. Similar to Whitson et al.s study, many gymnasts in this study acknowledged the usefulness of enrolling a nutritionist. However, some coaches described how they found attempting to enrol nutritionists to be a waste of time because the athletes lied to the nutritionists about what they normally ate. Natalie, an aerobics coach, reported:

the hardest thing is dieticians. And it's not that the dieticians aren't good, they are good, the ones we use. The problem is getting the athlete to listen to them ... They don't necessarily give all the information. For example, the dietician tells them to fill out a food diary for three days. So they change their diet for those three days.

Amy, a trampolining coach, described the same experience of athletes doctoring their food diaries. A 'food diary' is supposed to act as an inscription, in documenting each day's actual consumption. However, as in the scallops domestication case described by Callon in his landmark study, the gymnasts have mixed responses to aligning themselves to the plan set out by the scientists. While some agreed with the scientists' reasoning that a proper diet is necessary to training and competing well, and aligned themselves to this task accordingly, others rejected this and therefore intéressement (Callon, 1986) did not occur.

Natalie's and Amy's experiences highlighted the difficulty of making the internal workings of the body visible, a difficulty that technology is potentially able to solve. For example, the technology of testing blood can reveal severe problems such as low iron. In such a circumstance, the technology acts as an intermediary in revealing the make-up of the blood and its deficiencies. By contrast, without such an intermediary there is no way for the nutritionist to know the precise food consumed by gymnasts short of following the gymnast around and observing exactly what they eat. The literary device of the food diary is created in order to make food intake visible; however, it fails to work because the gymnasts fail to enrol it. In a very extreme example of overcoming this difficulty, Johns (1998) described how in his study he discovered an incident where some gymnastics coaches physically locked gymnasts in their hotel rooms while away on tour so that they could police the gymnasts' food intake. 


\section{Non-enrolment}

The majority of discussions about sports scientists and coaches assume from the outset that it is the coach and gymnast who can learn from the sports scientist. It is assumed that the scientists have specialist knowledge which it will benefit the coach to learn. However, coaches with great confidence in their knowledge often did not enrol sports scientists because they had previous experiences of scientists interfering with their programmes in a negative way. For example, Anna, a women's coach, described how one of her athletes visited a sports psychologist in order to reduce her fear of performing a new skill. The psychologist made suggestions to Anna to assist the gymnast, which Anna, using the knowledge derived from her coaching experience, believed to be absurd. Consequently, Anna made a deliberate decision not to enrol any other psychologists into her programme. Liam, another women's coach, agreed with Anna's view that his own psychology training was sufficient and that enrolling a psychologist could in fact confuse the issue: 'I'm not a great believer in it. I think that sometimes psychology can make you think too deep rather than thinking about what you actually need to do.' Like the medical professionals in Mol's (2002) study described earlier, Anna and the psychologist came to the gymnast's problem with two different sorts of training, which resulted in differing understandings about the problem. Anna's coaching knowledge leaned her in a different direction from the psychologist with specialist psychology knowledge. In confirmation of Anna and Liam's opinion that they had sufficient psychological knowledge on their own, Cote et al's (1995) study of the coaching skills of seventeen elite gymnastics coaches found that the ability to prepare gymnasts psychologically for competition was considered a standard skill.

My New Zealand study also found that lack of enrolment of sports scientists by coaches came about because, as in both Anna and Liam's cases, coaches have often studied sports science in order to gain their coaching qualifications. They possess the academic knowledge that legitimises the sports science profession (Abbott, 1988). In New Zealand all coaches need to have attended some short sports science sessions in order to be permitted to coach, a practice that is policed at competitions. Many have either a Bachelor of Physical Education or a coaching qualification which will have required them to pass sports science courses. Coaches who had studied in other countries were often even more highly qualified. For example, there are now a large number of coaches in New Zealand who received qualifications under the former Soviet-run system (Kerr and Moore, 2015). These coaches were required to attend four to 
six years of university, where they passed numerous courses in sports science disciplines as well as specialist gymnastics courses. These coaches often resist enrolling specialist sports scientists as they believe their own knowledge to be equal to or greater than many New Zealand sports scientists. For example, Amy, a trampoline coach, described how, although she enrols nutritionists to give talks to her trampolinists, she monitors their eating and their food diaries as she describes herself as having qualifications in this area. Similarly, Jessica, a women's coach, described how she saw no need to enrol a sports psychologist as she majored in psychology at university.

The strongest example of how coaches may have identical knowledge to sports scientists, causing coaches to resist enrolling scientists, occurred in the area of biomechanics. Judy, a biomechanist and women's coach, described the crossover between the work of the artistic gymnastics coach and the biomechanist to be a 'grey, murky area', with the two roles having many similarities. This became very apparent through the lack of enrolment of a biomechanist, Jim, who happened to have offices connected to a women's and men's artistic gymnasium and was keen to be enrolled in the programme on a voluntary basis. Jim described how he had found the elite coaches in the club to be uninterested in his help and would not enrol him, whereas the lower-level coaches were the opposite. Jim demonstrated how, through using his computer, he had assisted a non-elite coach with teaching a gymnast a very difficult skill. Jim and the coach used a method of trial and error. The gymnast would attempt the skill, then Jim would video the attempt, take the footage back to his computer, analyse it, compare it with other top athletes, then come back to the gymnasium and suggest corrections. The gymnast would try it again, and Jim would repeat the process until they succeeded. Although ultimately Jim's method resulted in the gymnast eventually learning the skill, this approach contrasted very strongly with how a very experienced and successful elite coach, who had coached world and Olympic medallists, taught the skill. The experienced coach directed the gymnast to perform a number of carefully crafted 'lead-up' drills before attempting the skill. He changed the gymnast's conditioning programme to ensure they had the necessary strength and flexibility to perform the move. Then the gymnast worked through a number of 'progression' skills, until finally attempting the skill with the coach assisting, and then by themselves. Cote et al. (1995) described this as the dominant method used by coaches to teach gymnasts new skills. A priority of this system is the fact that the gymnast is safe when attempting the skill for the first time. By contrast, when Jim's gymnast attempted the skill, he landed very painfully a number of times. Despite this, because Jim was 
successful in teaching the skill, he made the assumption that this ability would be a useful tool for the elite coaches and was surprised they did not want to work with him and learn from him. He was not aware that the elite coaches felt they already had the knowledge that he wanted to provide. This led to Jim losing respect for the coaches in assuming they did not want to learn from him, and the coaches losing respect for Jim in assuming he did not want to learn from them.

In this final example, the coaches and the biomechanist approached the situation with very different sets of understanding and produced gymnastics through very different actor-networks. Each utilised different technologies that produced different outcomes. The biomechanist used video plus specialist computer software, while the coach used a range of equipment from the gymnasium. The different understandings, and the resultant actor-networks that each professional produced, meant that neither network was able to extend to enrol the other.

\section{Conclusion}

This chapter introduced the work of one of the most prominent ANT theorists who works in the area of health and medicine: Annemarie Mol. This chapter found Mol's (2002) work to be very useful in a sporting context for examining how medical practitioners bring different understandings to their work, which leads to differing outcomes for athletes, including the 'performance' of particular diseases or injuries. This chapter used Mol's work to examine the use of alternative practitioners in Pike's (2005) study of rowers in the UK. The rowers were found to adopt the sport ethic strongly and both adopted and resisted the bio-medical model when seeking medical treatment, which led to them at times accepting the advice of certain doctors while rejecting that of others. In particular, the rowers were found to favour the use of alternative practitioners owing to their lack of use of the bio-medical model, which resulted in the athletes being able to be active in their treatment rather than being treated as machines or commodities to be fixed. The athletes further appreciated the way the alternative practitioners adopted a holistic understanding of the body rather than focusing on specific agents as problems. In doing so, these practitioners deliberately went against the bio-medical paradigm.

Mol's (2002) work was also of interest because of its demonstration of ANT methodology. As previously discussed, methodology is central to the use of ANT, 
given the emphasis on including the non-human and human and the inclusion of a detailed description that acts as the entire explanation for a phenomenon. In this chapter the second case, examining gymnastics in New Zealand, demonstrated the ANT methodology at work, since ANT methods were adopted from the outset. This case describes the actions of the gymnasts and coaches along with any non-humans that were identified as significant, in order to understand why particular sports scientists were enrolled into the gymnastics actor-network while others were not.

Both the studies examined in this chapter identified one of the central issues in sports medicine: the boundaries between the different professions. While Theberge (2008) uses Abbott's work on professions to examine this issue in relation to the integration of chiropractors into the line-up of sports medical professionals, in this chapter I suggest that focusing on the different understandings and the concept of enrolment can be equally fruitful in understanding how different professions become part of a particular field. The ANT emphasis on the enrolment process rather than individual beliefs shifts the focus to why action occurs or does not occur, and therefore why a particular field stabilises or changes.

In the case of sports science, it would be easy to assume that enrolling scientists into the sports training environment would be unproblematic. As Safai (2003) points out, sports scientists are specifically trained to rehabilitate sporting bodies and to assist them to work at their fullest potential. However, this chapter reveals how performance enhancement is an insufficient motivation for ensuring the enrolment of scientists by athletes and coaches. In both studies, participants were found to hold strong views that did not correspond with those of the sports scientists and prevented enrolment. The first study found that rowers opted to enrol alternative practitioners who were not as strongly attached to the bio-medical model in order to adhere to the sport ethic. The second study found that gymnasts and trampolinists, and their coaches, did not have enough confidence that the scientists were sufficiently versed in their sports to believe that enrolment would have any effect. These findings suggest that the assumption that athletes are now commonly surrounded by a competent medical team that proves crucial to their performance success is questionable. Instead, this chapter suggests that athletes and coaches make varied decisions based on their own actor-networks, which include individualised sports science training and perspectives. Consequently, the enrolment of sports scientists is highly unstable and can involve unexpected scientists. 